\title{
The role of endothelial nitric oxide in the anti-restenotic effects of liraglutide in a mouse model of restenosis
}

Hideki Kushima $^{\dagger}$, Yusaku Mori ${ }^{*}$ (D), Masakazu Koshibu, Munenori Hiromura, Kyoko Kohashi, Michishige Terasaki, Tomoyasu Fukui and Tsutomu Hirano*

\begin{abstract}
Background: Previous animal studies have shown that glucagon-like peptide-1 receptor agonists (GLP-1RAs) suppress arterial restenosis, a major complication of angioplasty, presumably through their direct action on vascular smooth muscle cells. However, the contribution of vascular endothelial cells (VECs) to this process remains unknown. In addition, the potential interference caused by severe hyperglycemia and optimal treatment regimen remain to be determined.
\end{abstract}

Methods: Nine-week-old male C57BL6 (wild-type) and diabetic db/db mice were randomly divided into vehicle or liraglutide treatment groups (Day 1), and subject to femoral artery wire injuries (Day 3). The injured arteries were collected on Day 29 for morphometric analysis. Human umbilical vein endothelial cells (HUVECs) were used for in vitro experiments. One-way ANOVA, followed by Tukey's test, was used for comparisons.

Results: In wild-type mice, liraglutide treatment $(5.7,17$, or $107 \mathrm{nmol} / \mathrm{kg} /$ day) dose-dependently reduced the neointimal area (20,50, and 65\%) without inducing systemic effects, and caused an associated decrease in the percentage of vascular proliferating cells. However, these effects were completely abolished by the nitric oxide synthase (NOS) inhibitor $\mathrm{N}$-omega-nitro-L-arginine methyl ester. Next, we investigated the optimal treatment regimen. Early treatment (Days 1-14) was as effective in reducing the neointimal area and vascular cell proliferation as full treatment (Days 1-29), whereas delayed treatment (Days 15-29) was ineffective. In HUVECs, liraglutide treatment dose-dependently stimulated NO production, which was dependent on GLP-1R, CAMP, CAMP-dependent protein kinase, AMP-activated protein kinase (AMPK), and NOS. Subsequently, we investigated the role of liver kinase B (LKB)-1 in this process. Liraglutide increased the phosphorylation of LKB-1, and siRNA-induced LKB-1 knockdown abolished liraglutidestimulated NO production. In severe hyperglycemic $\mathrm{db} / \mathrm{db}$ mice, liraglutide treatment also suppressed neointimal hyperplasia, which was accompanied by reductions in vascular cell proliferation and density. Furthermore, liraglutide treatment suppressed hyperglycemia-enhanced vascular inflammation 7 days after arterial injury.

Conclusions: We demonstrate that endothelial cells are targets of liraglutide, and suppress restenosis via endothelial NO. Furthermore, the protective effects are maintained in severe hyperglycemia. Our findings provide an evidence base for a future clinical trial to determine whether treatment with GLP-1RAs represents potentially effective pharmacological therapy following angioplasty in patients with diabetes.

Keywords: Endothelium, GLP-1 receptor agonist, Mouse, Nitric oxide, Restenosis

\footnotetext{
*Correspondence: u-mori@med.showa-u.ac.jp;

hirano@med.showa-u.ac.jp

${ }^{\dagger}$ Hideki Kushima and Yusaku Mori contributed equally to this work

Department of Internal Medicine, Division of Diabetes, Metabolism,

and Endocrinology, Showa University School of Medicine, 1-5-8

Hatanodai, Shinagawa, Tokyo 142-8555, Japan
} 


\section{Background}

Glucagon-like peptide receptor-1 agonists (GLP-1RAs) have been widely used for the treatment of type 2 diabetes owing to their robust glucose-lowering effects, which are accompanied by a reduction in body weight [1] Recent studies have revealed that GLP-1 is involved in the regulation of multiple physiological processes in various extra-pancreatic tissues, including the cardiovascular system [2]. Preclinical studies, conducted by ourselves and others, have identified the anti-atherogenic effects of GLP-1RAs, which were shown to be partly independent of their metabolic activities [3-9]. Accordingly, two large recent clinical trials, liraglutide effect and action in diabetes: evaluation of cardiovascular outcome results (LEADER) and evaluate cardiovascular and other longterm outcomes with semaglutide in subjects with type 2 diabetes (SUSTAIN-6), have revealed that treatment with GLP-1RAs significantly suppresses major adverse cardiovascular events in patients with type 2 diabetes who are at a high risk for cardiovascular disease. The findings suggest that GLP-1RAs exhibit vascular protective properties $[10,11]$.

Several animal studies have also shown that GLP-1RAs suppress vascular restenosis [12-15], which shares some pathophysiological similarities with atherosclerosis [16]. Vascular restenosis is one of the major complications of percutaneous transluminal angioplasty (PTA), mainly caused by neointimal hyperplasia, an exaggerated healing process of the damaged intima $[17,18]$. Restenosis leads to a narrowing of the artery and ultimately results in additional revascularization. Long-term patency following PTA is markedly improved by the use of drugeluting stents (DES), which strongly suppress neointimal hyperplasia by inhibiting the proliferation of vascular smooth muscle cells (VSMCs). However, their beneficial effects are reduced in patients with diabetes [19, 20], leaving them at a high risk for restenosis. The suppression of neointimal hyperplasia by GLP-1RAs was evaluated in vivo using mouse femoral artery wire injury and rat carotid artery balloon injury models [12-15]. These models, unlike atherosclerosis models, facilitate the evaluation of the direct vascular effects of an agent in the absence of metabolic abnormalities such as hypercholesterolemia [21]. The direct vascular effects of GLP-1RAs, identified by these studies, support their potential pharmacological use in the treatment of restenosis.

The main pathophysiology of neointimal hyperplasia is VSMC proliferation and migration, resulting from a switch from a contractile to a synthetic phenotype at the site of arterial injury [16]. Previous studies have reported the anti-proliferative and anti-migration effects of GLP$1 R A s$ on VSMCs in vitro $[12,13,22,23]$. These effects were proposed to underlie the GLP-1RA-mediated suppression of neointimal hyperplasia. However, vascular endothelial cells (VECs) also play an essential role in the suppression of neointimal hyperplasia, and VEC-derived nitric oxide $(\mathrm{NO})$ mediates this effect by inhibiting the phenotypic switching of VSMCs [24-26]. Numerous studies have revealed that GLP-1RAs exert their actions on VECs and enhance endothelial function such as NO production in vitro and NO-dependent vasodilation ex vivo [27-30]. It is known that DES trigger endothelial dysfunction at the site of stenting, leading to restenosis caused by thrombosis and atherosclerosis [24, 25]. Thus, VECs may represent a target for GLP-1RAs in the suppression of restenosis. Therefore, treatment with GLP1RAs represents potentially effective pharmacological therapy, following PTA with DES. However, the roles of VECs in the anti-restenotic effects of GLP-1RAs remain to be elucidated.

Another question relates to the initiation time and duration of the optimal treatment. In previous animal model studies, GLP-1RA treatment at a single dose was always initiated before arterial injury and continued throughout the experiment. It therefore remains to be determined whether shorter pre- or post-treatment suppresses restenosis. In addition, mildly hyperglycemic rats, with fasting plasma glucose levels of around $180 \mathrm{mg} / \mathrm{dL}$, were only employed in one previous study [15]. Therefore, it remains unclear whether the anti-restenotic effects of GLP-1RAs also occur in the presence of severe hyperglycemia, unlike their actions on pancreatic $\beta$ cells [31].

In the present study, we demonstrated that treatment with liraglutide dose-dependently suppressed neointimal hyperplasia in vivo; this effect was abrogated by the NO synthase (NOS) inhibitor $N$-omega-nitro-L-arginine methyl ester (L-NAME), indicating that endothelial NO mediates the anti-restenotic effects of liraglutide. Furthermore, liraglutide-stimulated NO production and phosphorylation of endothelial NOS (eNOS) were abolished by liver kinase B1 (LKB1) knockdown in vitro, proposing an essential role of LKB1 in these effects of liraglutide. Moreover, short treatment initiated before, but not after, the injury was as effective in suppressing restenosis as full treatment, and liraglutide exerted antirestenotic effects in $\mathrm{db} / \mathrm{db}$ mice with severe hyperglycemia. Our findings justify further studies employing larger animals, such as rabbits and pigs, which would provide better clinical models. Our findings also provide an evidence base for a future clinical trial to determine whether treatment with GLP-1RAs represents potentially effective pharmacological therapy, following PTA with DES in patients with diabetes. 


\section{Methods}

In the present study, we aimed to clarify the role of VECs in the anti-restenotic effects of the GLP-1RA liraglutide and examine the underlying mechanism by employing restenosis mouse models and cultures of human VECs. Furthermore, we investigated the efficacy of treatment using different initiation times and durations, and the influence of severe hyperglycemia on the anti-restenotic effects of GLP-1RA.

\section{Chemical agents}

The chemical agents were purchased as follows: liraglutide from Novo Nordisk Japan (Chiyoda, Tokyo, Japan); exendin-(9-39) (Ex-9) from AnaSpec (Fremont, CA, USA); L-NAME, SQ22536 (SQ), cAMP-dependent protein kinase (PKA) inhibitor fragment 14-22 myristoylated trifluoroacetate salt (PKI[14-22]), ESI-09, STO-609, and N-omega-nitro-L-arginine methyl ester (L-NAME) from Sigma-Aldrich Japan (Shinagawa, Tokyo, Japan); 10-(4'-[[N-diethylamino]]butyl)-2-chlorophenoxazine (Akt inhibitor X) was purchased from Santa Cruz (Dallas, Texas, USA) and dorsomorphin dihydrochloride from Wako (Osaka, Osaka, Japan).

\section{Animal experiments}

The study design was approved by the animal care committee of Showa University School of Medicine, and animal experiments were conducted in strict adherence to the Guide for the Care and Use of Laboratory Animals (8th edition, 2011; Office of Laboratory Animal Welfare, National Institutes of Health, MD, USA). All invasive procedures were performed under general anesthesia using isoflurane. Seven-week-old male C57BL6J (wildtype) and $\mathrm{db} / \mathrm{db}$ mice were purchased from Sankyo Labo Service (Edogawa, Tokyo, Japan) and housed in clean cages (3 mice per cage, maximum) in the Division of Animal Experimentation of Showa University School of Medicine. After a 2-week acclimatization period, mice were randomly divided into vehicle or liraglutide treatment groups. We conducted five animal experiments. The experimental design and treatment groups are shown in Fig. 1. The dose of liraglutide was $17 \mathrm{nmol} /$ $\mathrm{kg} /$ day, unless otherwise specified $[3,7,8]$. Agents were delivered using osmotic pumps (Alzet minipump 1002; Cupertino, CA, USA) subcutaneously implanted on Day 1 , and the pumps were replaced on Day 15 to avoid liraglutide degradation. L-NAME (20 mg/kg/day), a NOS

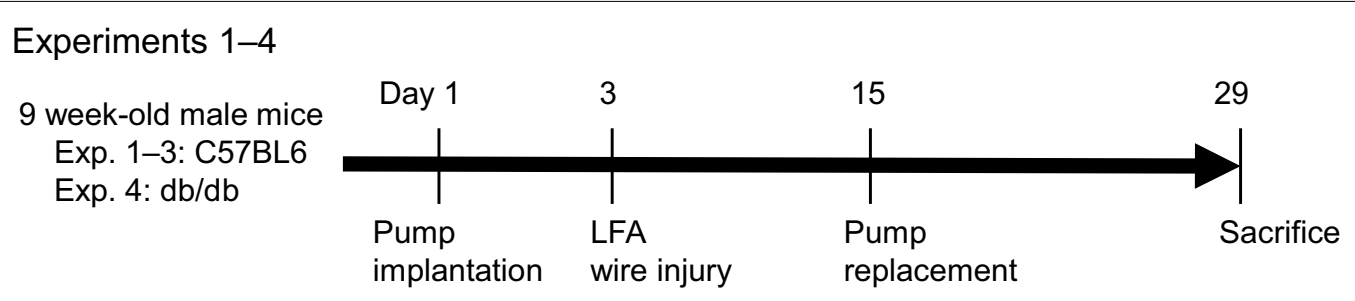

Treatment

Exp. 1: saline or liraglutide at $5.7,17$, or $107 \mathrm{nmol} \mathrm{kg}^{-1} \mathrm{~d}^{-1}$.

Exp. 2: saline, liraglutide, L-NAME $\left(20 \mathrm{mg} \mathrm{kg}^{-1} \mathrm{~d}^{-1}\right)$, or liraglutide + L-NAME

Exp. 3: saline or liraglutide, administered on Days 1-14, 15-29, or 1-29.

Exp. 4: saline or liraglutide

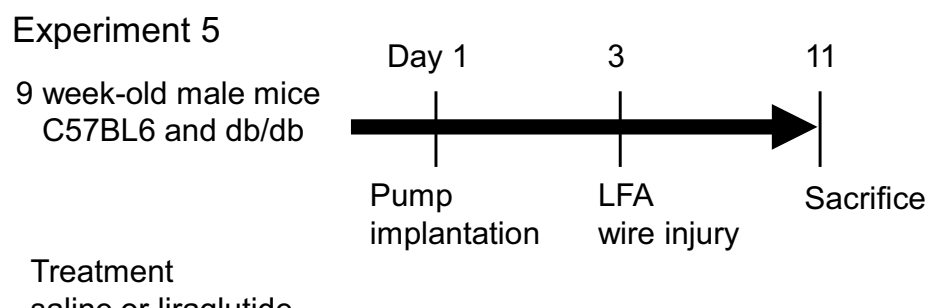

Fig. 1 Design of animal experiments (1-5). The liraglutide dose was 17 nmol/kg/day, unless otherwise specified. $N$-omega-nitro- - -arginine methyl ester (L-NAME) was administered via drinking water at the dose of $20 \mathrm{mg} / \mathrm{kg} /$ day; LFA, left femoral artery 
inhibitor, was administered via drinking water [26]. On Day 3, mice underwent left femoral artery wire injury, as previously reported by Sata and co-workers, with a few modifications [21]. Briefly, the left femoral artery was carefully isolated from the surrounding connective tissues through a small skin incision made in the left inguinal region. A straight spring wire $(0.38-\mathrm{mm}$ diameter, No. C-SF-15-15; Cook Japan, Nakano, Tokyo, Japan) was retrogradely inserted into the femoral artery via a small cut on the muscle branch. The wire was inserted to a depth of $7.5 \mathrm{~mm}$ and withdrawn after $1 \mathrm{~min}$. The muscle branch was ligated proximal to the cut to prevent bleeding, and the skin incision was sutured. Xylocaine (1\%) was added dropwise to the incision area to maintain tissue hydration keep tissues wet and relieve pain. Following the procedure, mice recovered in a separate cage for $6 \mathrm{~h}$ under careful observation, after which they were returned to their original cages. The mice did not show any signs of severe complications such as claudication or necrosis of the injured extremity, surgical site infection, or massive weight loss ( $20 \%$ of the baseline). Mice were killed by an overdose of inhaled isoflurane, and the injured arteries (5.5 $\mathrm{mm}$ long, from the site of the ligation) were collected on Day 29 for morphometric analyses (experiments 1-4) or on Day 11 for gene expression analyses (experiment 5).

\section{Assessment of plasma levels}

Blood samples were collected after 6-8 h fasting. Plasma glucose levels were measured using a dextrometer (Stat strip XP2, Nipro, Osaka, Osaka, Japan). Hemoglobin A1c (HbA1c) and plasma lipid levels were determined using a latex-enhanced immunoassay and an enzymatic colorimetric assay, respectively (Cobas, Roche Diagnostics Japan, Minato, Tokyo, Japan). Plasma active GLP-1 levels were measured by ELISA (High Sensitivity GLP-1 Active ELISA Kit, EMD Millipore, Billerica, MA, USA).

\section{Measurement of blood pressure}

Blood pressure and pulse rates were measured at the end of the experiments, using the tail-cuff method (Model MK-2000ST; Muromachi Kikai, Chuo, Tokyo, Japan). The average value obtained from 3 to 5 consecutive measurements was used as a single data point.

\section{Morphometric analysis}

Injured arteries were collected for morphometric analysis following perfusion fixation with PBS and 4\% paraformaldehyde. Three serial cross-sections taken from the proximal end of the paraffin-embedded femoral arteries at $0.5-\mathrm{mm}$ intervals were stained with Elastica van Gieson (EVG), and the average of three serial cross-sections was used as a single data point. The sections were digitized using an inverted microscope (Model IX71,
Olympus, Shinjyuku, Tokyo, Japan) and analyzed using Image J software (National Institutes of Health, Bethesda, MD, USA) by an investigator blinded to the treatment. The areas within the internal elastic lamina and the external laminal perimeter were defined as the neointima and the artery perimeter. Arteries completely occluded by the thrombus were excluded from analysis (Additional file 1: Figure S1a-c). Sections showing the following features were also excluded from analysis (Additional file 1: Figure S1d-f): broken wall structure, a branch of another artery, and missing elastic lamina. The percentage of excluded arteries and sections in each treatment group was approximately $10-20$ and 15-25\%, respectively. Fisher's exact test revealed no difference between the groups.

\section{Immunohistochemistry}

Proliferating and endothelial cells were identified by immunostaining using an anti-Ki67 antibody (Thermo Fisher Scientific Japan, Yokohama, Kanagawa, Japan, RM-9106-S1, RRID: AB_149792, raised in rabbit, 1: 250) and an anti-CD31 antibody (Abcam Japan, Chuo, Tokyo, Japan, ab28364, RRID: AB_726362, raised in rabbit, 1: 200), respectively. Nuclei were counterstained with hematoxylin. The averages of three serial cross-sections were used as single data points.

\section{Reverse transcription-polymerase chain reaction (RT-PCR) analysis}

In experiment 5, uninjured and injured femoral arteries were harvested 7 days after injury (Day 11). Total RNA extracted from the arteries was used for synthesizing complementary DNA as previously described [32]. Gene expression was assessed by real-time RT-PCR using the TaqMan gene expression assay and sequence detection system (ABI PRISM 7900; Life Technologies Japan, Minato, Tokyo, Japan). The following pre-designed TaqMan probe sets were used: Glp-1r, Mm00445292_m1; interleukin (Il)-1, Mm00434228_m1; Il-6, Mm00446190_

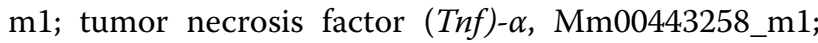
monocyte chemotactic protein $(M c p)-1, \mathrm{Mm} 00441242$ $\mathrm{m} 1$; transforming growth factor (Tgf)- $\beta$, Mm01178820 $\mathrm{m} 1$. The $18 \mathrm{~S}$ ribosomal RNA probe (18sRNA, Mm03928990_g1) was used as an internal control.

\section{Cell culture}

Human umbilical vein endothelial cells (HUVECs) were obtained from Lonza Japan (Chuo, Tokyo, Japan) and cultured in EBM-2 medium supplemented with FBS and growth factors (Lonza Japan). Collagen I-coated flasks or plates were used for all cell culture experiments. The cells were seeded onto 24-well plates at the following density per well: $2.5 \times 10^{4}$ for NO measurements, $1.0 \times 10^{4}$ for cell proliferation assays, and $4 \times 10^{4}$ for protein 
extraction and siRNA transfection. Cells were starved in M199 containing 0.3\% FBS for $1 \mathrm{~h}$ for NO measurements, and in $0.1 \%$ FBS containing EBM-2 (without growth factors) for $6 \mathrm{~h}$ for protein extraction. For cell culture experiments involving treatment with high levels of glucose, cells were exposed to $25 \mathrm{mmol} / \mathrm{L}$ glucose for $48 \mathrm{~h}$ before seeding. Cells between passages 4-8 were used for the experiments.

\section{Measurement of NO production}

Plasma NO levels and NO production by HUVECs was determined by measuring the stable metabolites of $\mathrm{NO}$ $\left(\mathrm{NO}_{2}\right.$ and $\left.\mathrm{NO}_{3}\right)$ in the culture medium (Nitrate/Nitrite Fluorometric Assay Kit; Dojin, Kamimashiki, Kumamoto, Japan) [33]. Protein in plasma samples was removed by ultrafiltration (Pierce concentrator, PES, $10 \mathrm{~K} \mathrm{MWCO;}$ Thermo Fisher Scientific Japan) before measurement. HUVECs were stimulated with the indicated concentrations of agents (saline or liraglutide $0.1-100 \mathrm{nmol} / \mathrm{L}$ ) for $2 \mathrm{~h}$, following serum starvation in M199 with 0.3\% FBS for $1 \mathrm{~h}$. Inhibitors were added $30 \mathrm{~min}$ prior to stimulation at the following concentrations: GLP-1R antagonist Ex-9, $100 \mathrm{nmol} / \mathrm{L}$; cAMP inhibitor SQ, $100 \mu \mathrm{mol} / \mathrm{L}$; PKA inhibitor PKI (14-22), $1 \mu \mathrm{mol} / \mathrm{L}$; exchange factor directly activated by cAMP (EPAC) inhibitor ESI09, $6.4 \mu \mathrm{mol} / \mathrm{L}$; calcium-calmodulin-dependent protein kinase kinase (CaMKK) inhibitor STO-609, $10 \mu \mathrm{mol} / \mathrm{L}$; AMP-activated protein kinase (AMPK) inhibitor dorsomorphine, $10 \mu \mathrm{mol} / \mathrm{L}$; Akt inhibitor X, $5 \mu \mathrm{mol} / \mathrm{L}$; NOS inhibitor L-NAME, $1 \mathrm{mmol} / \mathrm{L}$ [3, 27, 34-39]. The $\mathrm{NO}_{2}$ in the plasma samples and medium was converted to $\mathrm{NO}_{3}$ by $\mathrm{NO}_{2}$ reductase after stimulation, and the medium was incubated with fluorescent 2,3-diaminonaphthalene for $15 \mathrm{~min}$. The fluorescence intensities were measured using an Infinite M200 PRO instrument (TECAN Japan, Kawasaki, Kanagawa, Japan).

\section{Western blot}

Proteins were extracted from HUVECs or mouse aortas using CelLytic M, containing cocktails of protease inhibitors and phosphatase inhibitors (all from SigmaAldrich Japan). Western blot was performed as previously described [40]. Briefly, $7 \mu$ g of protein per lane was electrophoresed in polyacrylamide gels and transferred to polyvinylidene fluoride membranes. The membranes were blocked with PVDF Blocking Reagent (TOYOBO, Osaka, Osaka, Japan) for $1 \mathrm{~h}$, and then incubated overnight with antibodies at the following dilutions: phosphorylated LKB1 at Ser 428 (p-LKB1; Cell Signaling Technology Japan, Chiyoda, Tokyo, Japan, \#3482, RRID: AB_2198321, raised in rabbit, 1: 2500), LKB1 (Cell Signaling Technology Japan, \#3050, RRID: AB_823559, raised in rabbit, 1: 5000), p-AMPK $\alpha$ at Thr 178 (p-AMPK; Cell
Signaling Technology Japan, \#2535, RRID: AB_331250, raised in rabbit, 1: 2500), AMPK $\alpha$ (Cell Signaling Technology Japan, \#2532, RRID: AB_330331, raised in rabbit, 1: 5000), p-eNOS at Ser 1177 (p-eNOS; Cell Signaling Technology Japan, \#9570, RRID: AB_2298588, raised in rabbit, 1: 2500), eNOS (Cell Signaling Technology Japan, \#32,027, RRID: not available, raised in rabbit, 1: 5000), and $\beta$-actin (Sigma-Aldrich Japan, A2066, RRID: AB_476693, raised in rabbit, 1: 8000). Goat antirabbit IgG conjugated with horseradish peroxidase (GE Healthcare Japan, Minato, Tokyo, Japan, NA934, RRID: AB_772206, raised in donkey) was used at a 1: 40,000 dilution. The Can Get Signal ${ }^{\circledR}$ Immunoreaction Enhancer Solution (TOYOBO) was used for antibody dilutions. The bands on the immunoblot were detected using the Amersham ECL Prime kit (GE Healthcare Japan) and quantified using Image J software.

\section{siRNA transfection}

Predesigned siRNAs for the negative control and LKB1 were purchased from Applied Biosystems (Silencer ${ }^{\circledR}$ Select Negative Control No. 2 siRNA; LKB1 siRNA, S74498; Foster City, CA, USA). The siRNAs were incubated for $30 \mathrm{~min}$ with the TransIT-TKO transfection reagent (Mirus Bio, Madison, WI, USA) in serum-free EBM-2, and the mixture was added to the medium at a final siRNA concentration of $25 \mathrm{nmol} / \mathrm{L}$. HUVECs were used for experiments $72 \mathrm{~h}$ post-transfection.

\section{Statistical analysis}

Data are expressed as mean \pm SEM. We conducted comparisons of more than two groups using a one-way ANOVA, followed by Tukey's test, and comparisons involving two groups using an unpaired $t$ test. Correlations were determined using Pearson's correlation coefficient test. The Jonckheere-Terpstra trend test was used for determining dose-effect relationships. Statistical calculations were performed using JMP software (version 12; SAS Institute Inc., NC, USA), except for the Jonckheere-Terpstra trend test, which was conducted with $\mathrm{R}$ software (Ver 3.2.2; Welthandelsplatz, Vienna, Austria). The significance level was defined at $\mathrm{p}<0.05$.

\section{Results}

Liraglutide dose-dependently suppresses neointimal hyperplasia after arterial injury

First, we investigated the dose-effect relationship of liraglutide against restenosis after arterial injury (animal experiment 1). Wild-type C57BL6 mice were treated with vehicle or increasing doses of liraglutide (5.7, 17, or $107 \mathrm{nmol} / \mathrm{kg} /$ day). The physiological and biochemical parameters measured are shown in Table 1. No differences were detected between the groups, except 
Table 1 Physiological and biochemical parameters of mice treated with vehicle or different doses of liraglutide

\begin{tabular}{lllll}
\hline & Vehicle & \multicolumn{3}{l}{ Liraglutide (nmol/kg/day) } \\
\cline { 3 - 5 } & & $\mathbf{5 . 7}$ & $\mathbf{1 7}$ & $\mathbf{1 0 7}$ \\
\hline Number & 5 & 5 & 6 & 5 \\
Food intake (g/day) & $4.2 \pm 0.2$ & $4.1 \pm 0.1$ & $3.8 \pm 0.2$ & $4.2 \pm 0.1$ \\
Water intake (g/day) & $4.9 \pm 0.2$ & $5.2 \pm 0.3$ & $5.7 \pm 0.1$ & $4.9 \pm 0.2$ \\
Initial BW (g) & $21.6 \pm 0.5$ & $22.6 \pm 0.4$ & $22.9 \pm 0.2$ & $22.5 \pm 0.5$ \\
Final BW (g) & $22.5 \pm 0.6$ & $23.0 \pm 0.8$ & $24.8 \pm 0.4$ & $25.0 \pm 0.4$ \\
Pulse rate (beats/min) & $704 \pm 15$ & $709 \pm 10$ & $717 \pm 14$ & $707 \pm 11$ \\
SBP (mmHg) & $126 \pm 3$ & $123 \pm 2$ & $120 \pm 5$ & $125 \pm 5$ \\
DBP (mmHg) & $72 \pm 7$ & $72 \pm 11$ & $66 \pm 11$ & $82 \pm 11$ \\
HbA1c (\%) & $5.1 \pm 0.4$ & $4.8 \pm 0.2$ & $4.7 \pm 0.2$ & $4.4 \pm 0.1$ \\
FPG (mg/dL) & $111 \pm 28$ & $98 \pm 9$ & $120 \pm 12$ & $112 \pm 20$ \\
TC (mg/dL) & $78 \pm 10$ & $67 \pm 11$ & $93 \pm 5$ & $91 \pm 6$ \\
TG (mg/dL) & $56 \pm 3$ & $51 \pm 3$ & $48 \pm 3$ & $61 \pm 3$ \\
Active GLP-1 (pmol/L) & $1.4 \pm 0.2$ & $2.2 \pm 0.3$ & $3.6 \pm 0.8$ & $8.4 \pm 3.9^{*+}$ \\
\hline
\end{tabular}

Food and water intake were measured throughout the experimental period. The other parameters were evaluated at the end of the experiment, except for initial body weight (BW). Data are expressed as mean \pm SEM

$S B P$ systolic blood pressure, $D B P$ diastolic blood pressure, $F P G$ fasting plasma glucose, TC total cholesterol, TG triglycerides, GLP-1 glucagon like peptide-1

${ }^{*} p<0.05$ vs. vehicle; ${ }^{\dagger} p<0.05$ vs. liraglutide $5.7 \mathrm{nmol} / \mathrm{kg} /$ day

for elevated levels of plasma active GLP-1 in groups treated with liraglutide. When evaluating morphometric changes, liraglutide treatment at 17 and $107 \mathrm{nmol} /$ $\mathrm{kg} /$ day significantly suppressed neointimal hyperplasia without inducing medial thinning or arterial dilation. These changes resulted in reductions in the intima to media (I/M) ratio. In contrast, treatment with a $5.7 \mathrm{nmol} /$ $\mathrm{kg} /$ day dose of liraglutide did not suppress neointimal hyperplasia (Fig. 2a-e). The Jonckheere-Terpstra trend test revealed a significant trend between the decreases in neointimal area and the increases in liraglutide doses $(\mathrm{p}<0.001)$.

\section{The anti-restenotic effects of liraglutide are mediated by NO}

Next, we focused on endothelial NO as a potential mediator of the anti-restenotic effects of liraglutide (animal experiment 2). Vehicle or liraglutide $(17 \mathrm{nmol} / \mathrm{kg} /$ day $)$ were administered to mice in the presence or absence of the L-NAME NOS inhibitor. In a subset of animals, we observed NOS inactivation by L-NAME treatment in vivo. Plasma NO levels were significantly lower in mice treated with L-NAME than in those treated with vehicle (Additional file 1: Figure S2a). Consistently, L-NAME treatment significantly suppressed phosphorylation of eNOS in the aorta compared to vehicle treatment (Additional file 1: Figure S2b, c). Table 2 shows the physiological and biological parameters of each treatment group. Mice treated with L-NAME exhibited higher systolic blood pressure levels than those not administered the inhibitor, as previously reported [41]. Co-treatment with

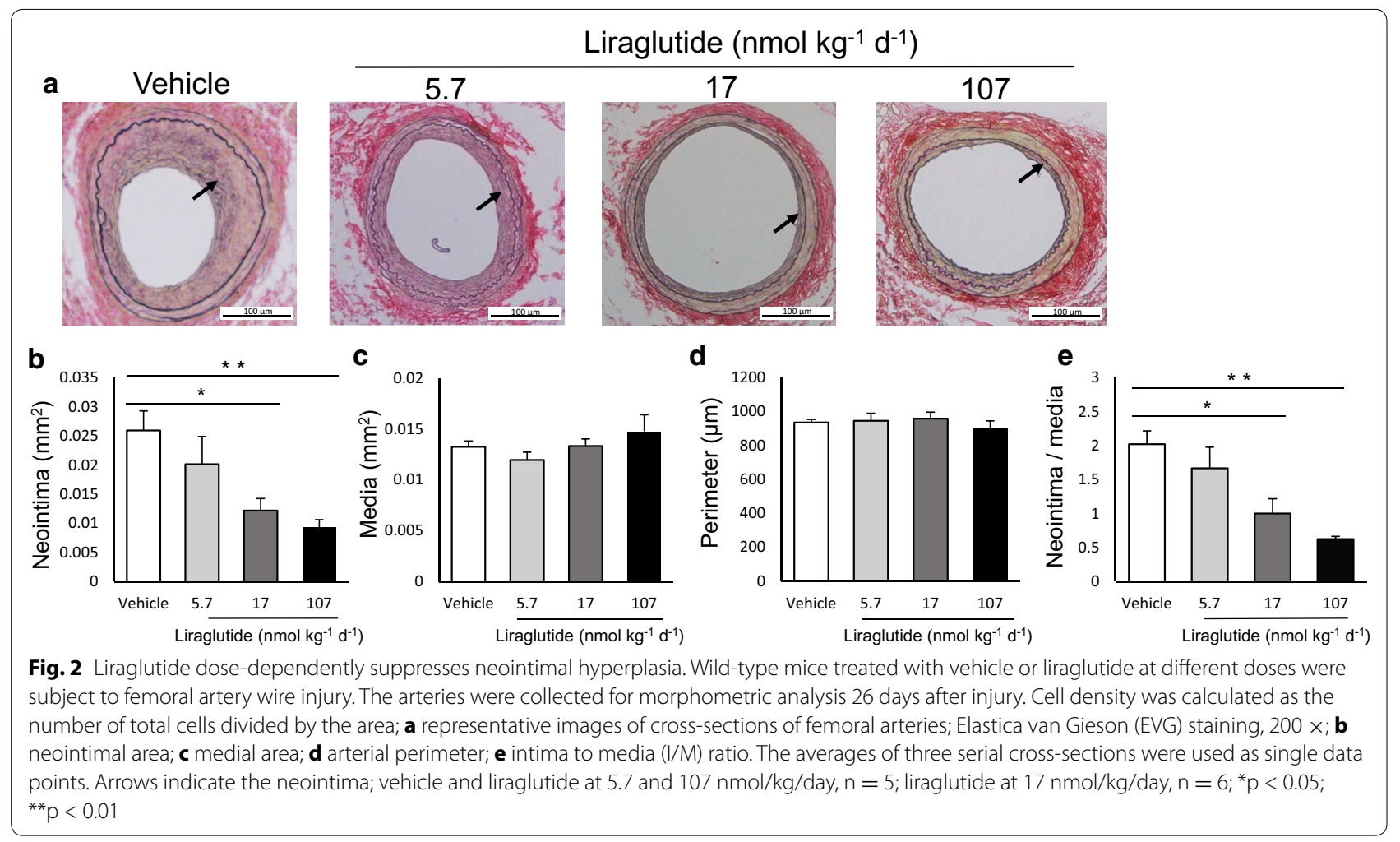


Table 2 Physiological and biochemical parameters of vehicle- or liraglutide-treated mice with or without $\mathrm{N}$-omega-nitroL-arginine methyl ester

\begin{tabular}{lllll}
\hline & Vehicle & Liraglutide & +L-NAME (20 $\mathbf{~ m g / k g / d a y ) ~}$ \\
\cline { 4 - 5 } & & & Vehicle & Liraglutide (17 $\mathbf{~ n m o l / k g / d a y ) ~}$ \\
\hline Number & 5 & 5 & 5 & 5 \\
Food intake (g/day) & $4.1 \pm 0.1$ & $3.6 \pm 0.3$ & $3.8 \pm 0.1$ & $4.2 \pm 0.1$ \\
Water intake (g/day) & $4.7 \pm 0.3$ & $5.3 \pm 0.5$ & $4.5 \pm 0.1$ & $5.0 \pm 0.1$ \\
Initial BW (g) & $22.4 \pm 0.7$ & $23.3 \pm 0.2$ & $21.7 \pm 0.3$ & $22.0 \pm 0.6$ \\
Final BW (g) & $22.9 \pm 0.6$ & $25.3 \pm 1.0$ & $22.5 \pm 0.1$ & $23.8 \pm 0.9$ \\
Pulse rate (beats/min) & $702 \pm 15$ & $712 \pm 16$ & $645 \pm 30$ & $660 \pm 24$ \\
SBP (mmHg) & $126 \pm 3$ & $120 \pm 6$ & $143 \pm 3^{*} \dagger$ & $130 \pm 3$ \\
DBP (mmHg) & $72 \pm 10$ & $71 \pm 13$ & $97 \pm 10$ & $80 \pm 10$ \\
HbA1c (\%) & $4.6 \pm 0.1$ & $4.5 \pm 0.1$ & $4.7 \pm 0$ & $4.7 \pm 0.1$ \\
FPG (mg/dL) & $121 \pm 10$ & $117 \pm 8$ & $120 \pm 12$ & $120 \pm 14$ \\
TC (mg/dL) & $89 \pm 2$ & $83 \pm 6$ & $90 \pm 3$ & $93 \pm 2$ \\
TG (mg/dL) & $49 \pm 1$ & $50 \pm 4$ & $54 \pm 1$ & $57 \pm 2$
\end{tabular}

Food and water intake were measured throughout the experimental period. The other parameters were evaluated at the end of the experiment, except for initial BW L-NAME N-omega-nitro-L-arginine methyl ester

${ }^{*} \mathrm{p}<0.05$ vs. vehicle; ${ }^{\dagger} \mathrm{p}<0.05$ vs. liraglutide

L-NAME completely abolished the suppression of neointimal hyperplasia by liraglutide, while the medial area and the arterial perimeter were not affected (Fig. 3a-e). Furthermore, liraglutide treatment decreased the percentages of intimal and medial proliferating cells, as assessed by cells that stained positive for the Ki-67 marker; however, these effects were not observed in mice co-treated with L-NAME (Fig. $3 \mathrm{f}-\mathrm{h}$ ). The number of proliferating cells in the neointima and media was correlated with neointimal hyperplasia and medial thinning, respectively (Table 3 ). In contrast, the density of neointimal or medial cells, calculated as the number of total cells divided by the area, was not affected by treatment with liraglutide or L-NAME (Fig. 3i, j).

\section{Early, but not delayed, treatment with liraglutide is as effective in the suppression of restenosis as full treatment}

To determine the optimal treatment regimen, we compared the anti-restenotic effects of early and delayed treatment (Days 1-14 and Days 15-29 days, respectively) with those achieved by full treatment (Day 1-29) (animal experiment 3 ). Figure 4a shows the experimental design. The formation of the neointima and endothelial regeneration, at different time points after arterial injury, are presented in Additional file 1: Figure S3. On Day 14, at the beginning of the delayed treatment, the neointima was not clearly noticeable; however, endothelial regeneration, as assessed by the CD31-positive area, was almost complete. Physiological and biochemical parameters were comparable between the groups (Table 4). Although treatment was terminated at Day 14, the early treatment group exhibited suppression of neointimal hyperplasia on Day 29, which was similar to that observed in the full treatment group (Fig. 4b-f). In contrast, this suppression was reduced in the delayed treatment group. Furthermore, early treatment was effective in reducing the proliferation of vascular cells, as assessed on Day 29 (Fig. 4g-i). Similar to neointimal hyperplasia, delayed treatment failed to suppress the proliferation of vascular cells.

\section{Liraglutide stimulates endothelial NO production via the GLP-1R/CAMP/PKA/AMPK/eNOS pathway in vitro}

To investigate the mechanism underlying the observed effects, we examined the molecules involved in liraglutide-stimulated NO production in vitro. Liraglutide treatment dose-dependently stimulated $\mathrm{NO}$ production in HUVECs, which was blocked by the Ex-9 GLP-1R antagonist (Fig. 5a). This effect was also completely abolished by the cAMP, PKA, AMPK, or NOS inhibitors, but not by the EPAC, CaMKK, or Akt inhibitors (Fig. 5b). Taken together, our data suggest that endothelial NO production induced by liraglutide is dependent on the GLP-1R/ cAMP/PKA/AMPK/eNOS pathway in vitro.

LKB1 is essential for liraglutide-stimulated NO production Next, we investigated the role of LKB-1 as a molecule that potentially links PKA to AMPK. Liraglutide treatment significantly increased the phosphorylation of LKB1 in HUVECs, consistent with the phosphorylation of AMPK and eNOS (Fig. 6a-d). Cells transfected with siRNA against LKB1 exhibited a 95\% decrease in LKB1 protein 


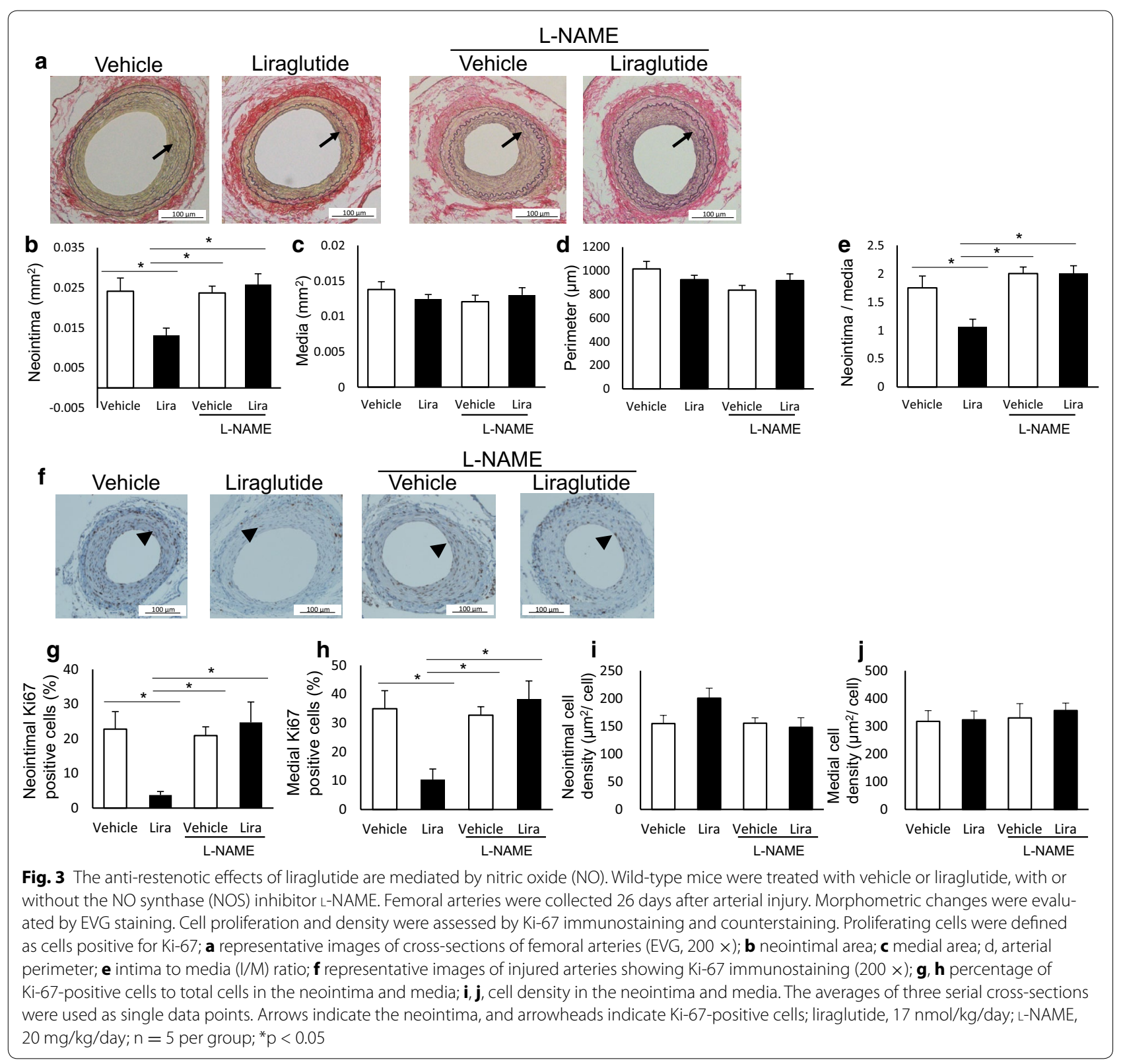

levels compared with cells transfected with scrambled siRNA (Fig. 6e, f). LKB1 knockdown abrogated the effects of liraglutide on NO production (Fig. 6g). Moreover, LKB1 knockdown inhibited liraglutide-induced phosphorylation of AMPK and eNOS (Fig. 6h-j).

\section{The anti-restenotic effects of liraglutide are preserved in severely hyperglycemic $\mathrm{db} / \mathrm{db}$ mice}

We examined whether the anti-restenotic effects of liraglutide were preserved under severe hyperglycemia in $\mathrm{db} / \mathrm{db}$ mice, a model of obesity-induced diabetes (animal experiment 4). At the time of treatment initiation (at the age of 9 weeks), all $\mathrm{db} / \mathrm{db}$ mice exhibited severe hyperglycemia (random plasma glucose levels over $300 \mathrm{mg} /$ $\mathrm{dL}$ ), and a significantly decreased Glp-1r expression in the aorta, compared to that in nondiabetic wild-type mice (Fig. 7a). First, we determined the dose of liraglutide to be administered. The body weights and the fasting plasma glucose levels of $\mathrm{db} / \mathrm{db}$ mice were significantly reduced following liraglutide treatment with $107 \mathrm{nmol} /$ $\mathrm{kg} /$ day compared with those of mice administered vehicle treatment, while treatment with $17 \mathrm{nmol} / \mathrm{kg} /$ day liraglutide did not affect body weight, and caused a slight decrease in fasting plasma glucose levels (Additional 
Table 3 Correlation of the neointimal and medial areas with the number of proliferating and total cells

\begin{tabular}{|c|c|c|c|c|c|}
\hline $\begin{array}{l}\text { Neointimal } \\
\text { area }\end{array}$ & $r$ & $p$ & Medial area & $r$ & $p$ \\
\hline Combined & & & Combined & & \\
\hline Intima & & & Intima & & \\
\hline Ki67+ cells & 0.48 & $<0.0001$ & Ki67+ cells & 0.04 & 0.73 \\
\hline Total cells & 0.85 & $<0.0001$ & Total cells & -0.44 & $<0.01$ \\
\hline Media & & & Media & & \\
\hline Ki67+ cells & -0.20 & 0.12 & Ki67+ cells & -0.30 & 0.02 \\
\hline Total cells & -0.21 & 0.10 & Total cells & 0.45 & $<0.01$ \\
\hline Vehicle alone & & & Vehicle alone & & \\
\hline Intima & & & Intima & & \\
\hline Ki67+ cells & 0.68 & $<0.01$ & Ki67+ cells & 0.09 & 0.70 \\
\hline Total cells & 0.92 & $<0.0001$ & Total cells & -0.31 & 0.19 \\
\hline Media & & & Media & & \\
\hline Ki67+ cells & -0.07 & 0.79 & Ki67+ cells & 0.00 & 0.99 \\
\hline Total cells & 0.13 & 0.60 & Total cells & 0.46 & 0.04 \\
\hline Liraglutide alone & & & Liraglutide alone & & \\
\hline Intima & & & Intima & & \\
\hline Ki67+ cells & 0.61 & $<0.01$ & Ki67+ cells & 0.37 & 0.06 \\
\hline Total cells & 0.88 & $<0.0001$ & Total cells & -0.35 & 0.08 \\
\hline Media & & & Media & & \\
\hline Ki67+ cells & -0.39 & 0.05 & Ki67+ cells & 0.00 & 0.98 \\
\hline Total cells & -0.39 & 0.05 & Total cells & 0.69 & $<0.0001$ \\
\hline
\end{tabular}

$r$ indicates Pearson's correlation coefficient; Combined, 63 sections taken from 31 mice; vehicle alone, 20 sections taken from 10 mice; liraglutide alone, 26 sections taken from 11 mice

file 1: Figure S4a, b). To avoid the potential influence of systemic effects, we chose a $17 \mathrm{nmol} / \mathrm{kg} /$ day dose of liraglutide for this experiment. The physiological and biochemical parameters are presented in Table 5. Fasting plasma glucose and HbA1c levels tended to be lower in liraglutide-treated mice ( $\mathrm{p}=0.20$ and 0.66 , respectively). Other parameters were similar between the groups, except for the pulse rate and plasma active GLP-1 levels. Treatment with liraglutide significantly suppressed neointimal hyperplasia compared with that achieved by treatment with the vehicle, without inducing medial thinning or arterial dilation (Fig. $7 \mathrm{~b}-\mathrm{f}$ ). In addition, liraglutide treatment reduced the percentage of neointimal and medial proliferating cells (Fig. $7 \mathrm{~g}-\mathrm{i}$ ). Further, the reduction in the number of neointimal proliferating cells was correlated with the neointimal area (Table 6). Liraglutide treatment also decreased intimal cell density, which was not changed in normoglycemic mice (Fig. 7j, k).

\section{Liraglutide stimulates endothelial NO production in a hyperglycemic milieu in vitro}

We examined the effects of hyperglycemia on liraglutide-stimulated endothelial NO production in vitro.
HUVECs were exposed to a high glucose concentration $(25 \mathrm{mmol} / \mathrm{L}) 96 \mathrm{~h}$ before the experiments. Liraglutide treatment significantly increased NO production in HUVECs cultured in high concentrations of glucose, as well as in those cultured under normal glucose conditions (Fig. 8a). Similarly, liraglutide treatment significantly increased the phosphorylation of LKB1, AMPK, and eNOS in HUVECs cultured in high-glucose media (Fig. 8b-e).

\section{Liraglutide suppresses the hyperglycemia-enhanced vascular expression of pro-inflammatory cytokines and Tgf- $\beta$ after arterial injury}

Finally, we investigated the anti-inflammatory effects of liraglutide in vivo (animal experiment 5 ). Femoral arteries were collected from a different set of animals 7 days after injury (Day 11). In normoglycemic wild-type mice, liraglutide did not affect the injury-induced vascular expression of pro-inflammatory cytokines, chemokines, or growth factors (Fig. 9a-e). In hyperglycemic $\mathrm{db} / \mathrm{db}$ mice, inflammatory responses to the injury were substantially enhanced compared with those in normoglycemic mice. Further, liraglutide treatment significantly suppressed the hyperglycemia-enhanced vascular expression of $\mathrm{Il}-1, \operatorname{Tnf}-\alpha$, and $T g f-\beta$, and tended to reduce $\mathrm{Il}-6$ and Mcp-1 levels (Fig. 9a-e).

\section{Discussion}

In the present study, we demonstrate for the first time that the anti-restenotic effects of liraglutide are abrogated by the L-NAME NOS inhibitor in vivo, and that LKB1 is essential for liraglutide-stimulated endothelial NO production in vitro. We additionally found that treatment initiated before, but not after, injury was as effective in suppressing restenosis as full treatment, and that liraglutide exerts anti-restenotic effects in $\mathrm{db} / \mathrm{db}$ mice with severe hyperglycemia.

Moreover, we demonstrated that liraglutide suppresses restenosis after arterial injury, consistently with previous animal studies [12-15]. Importantly, we identified a novel, clear dose-effect relationship between the dose of liraglutide and neointimal hyperplasia. Previous studies have shown dose-dependent suppression of the formation of atherosclerotic lesions following GLP-1RA treatment in mouse models of atherosclerosis [6]. Our findings suggest that a higher dose of GLP-1RA should be considered for the suppression of not only atherosclerosis but also restenosis. Notably, all vascular protective effects of liraglutide, including the suppression of vascular cell proliferation, were completely abolished by treatment with the L-NAME NOS inhibitor. Interestingly, the protective effects of endothelial NO against vascular remodeling are supported by several previous studies 


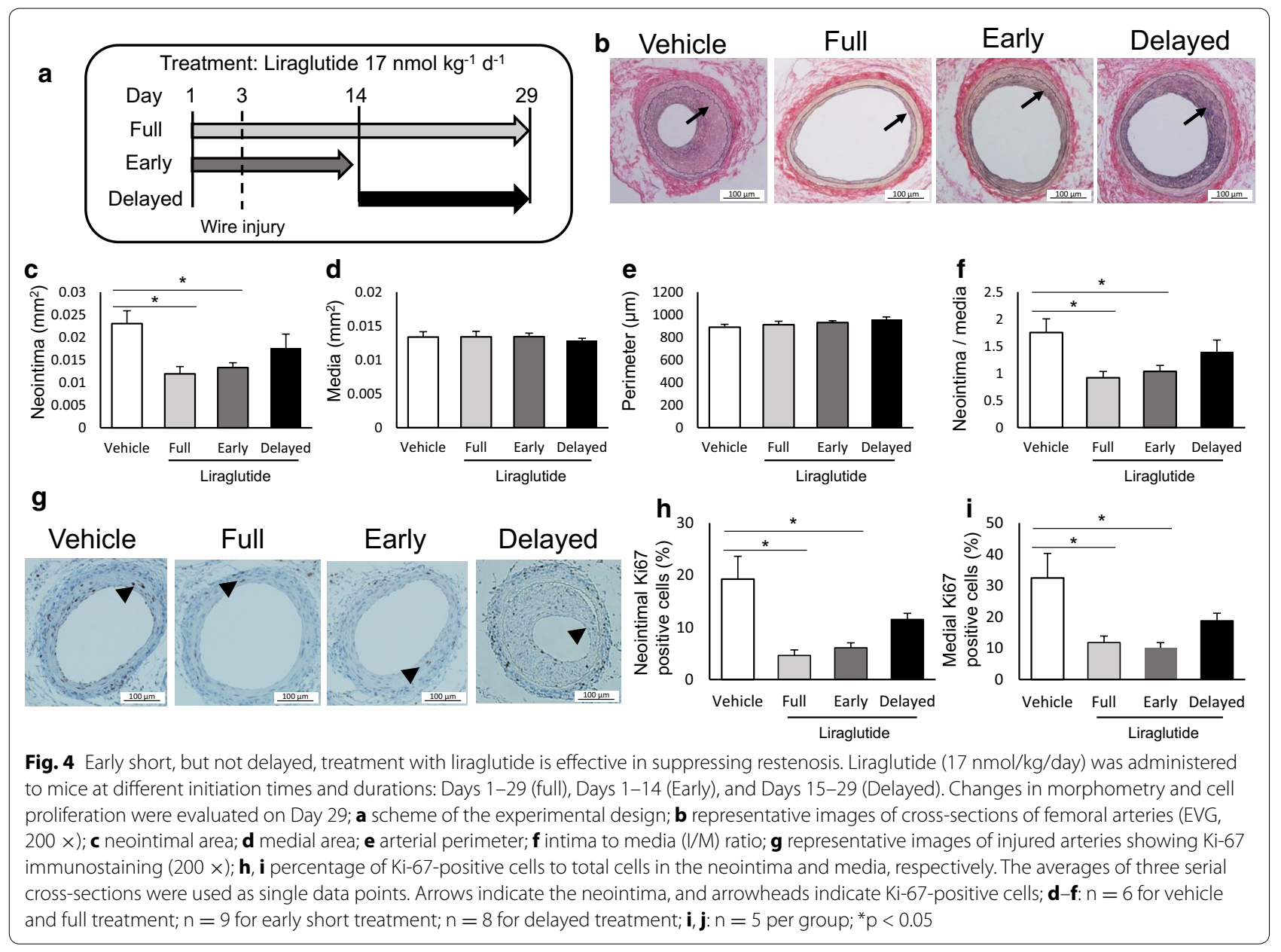

Table 4 Physiological and biochemical parameters of mice treated with vehicle or liraglutide

\begin{tabular}{lllll}
\hline & Vehicle & \multicolumn{3}{l}{ Liraglutide (17 nmol/kg/day) } \\
\cline { 3 - 5 } & & Full & Early & Delayed \\
\hline Number & 6 & 6 & 9 & 8 \\
Initial BW (g) & $21.2 \pm 0.4$ & $21.9 \pm 0.1$ & $22.3 \pm 0.3$ & $21.9 \pm 0.1$ \\
Final BW (g) & $22.6 \pm 0.5$ & $23.3 \pm 0.4$ & $23.3 \pm 0.3$ & $23.6 \pm 0.3$ \\
Heart rate (beats/min) & $696 \pm 28$ & $722 \pm 21$ & $722 \pm 8$ & $715 \pm 22$ \\
SBP (mmHg) & $124 \pm 2$ & $119 \pm 6$ & $110 \pm 4$ & $115 \pm 2$ \\
DBP (mmHg) & $68 \pm 13$ & $66 \pm 14$ & $43 \pm 6$ & $62 \pm 5$ \\
HbA1c (\%) & $4.6 \pm 0.2$ & $4.7 \pm 0.2$ & $4.7 \pm 0.0$ & $4.7 \pm 0.1$ \\
FPG (mg/dL) & $118 \pm 7$ & $114 \pm 13$ & $138 \pm 8$ & $136 \pm 10$ \\
TC (mg/dL) & $92 \pm 8$ & $89 \pm 4$ & $91 \pm 1$ & $91 \pm 3$ \\
TG (mg/dL) & $51 \pm 3$ & $52 \pm 3$ & $52 \pm 3$ & $60 \pm 3$ \\
\hline
\end{tabular}

Food and water intake were measured throughout the experimental period. The other parameters were evaluated at the end of the experiment, except for initial BW. The initiation time and the duration of liraglutide treatment were as follows: full, Days 1-29; Early, Days 1-14; Delayed, Days 15-29; the experiment design is illustrated in Fig. 3a
[24-26, 42]. Treatment with NO donors and transfection of the eNOS gene to the injured site have been shown to suppress restenosis in animal models [43, 44]. Thus, endothelial NO may play a crucial role in the liraglutideinduced suppression of neointimal hyperplasia and associated vascular cell proliferation.

We additionally sought to determine the optimal treatment initiation time and the duration of liraglutide administration. Both early and delayed treatments were initiated before neointimal formation, and the treatment period for each was the same (14 days). However, the two treatments led to different vascular outcomes. Early treatment was as effective in preventing neointimal hyperplasia as full treatment, while the delayed treatment failed to accomplish this. Similar effects for liraglutide against atherosclerosis have been reported in mice: liraglutide suppressed the formation of atheromatous plaque in younger apolipoprotein-null mice, but failed to suppress the progression of it in older mice [8]. Therefore, 

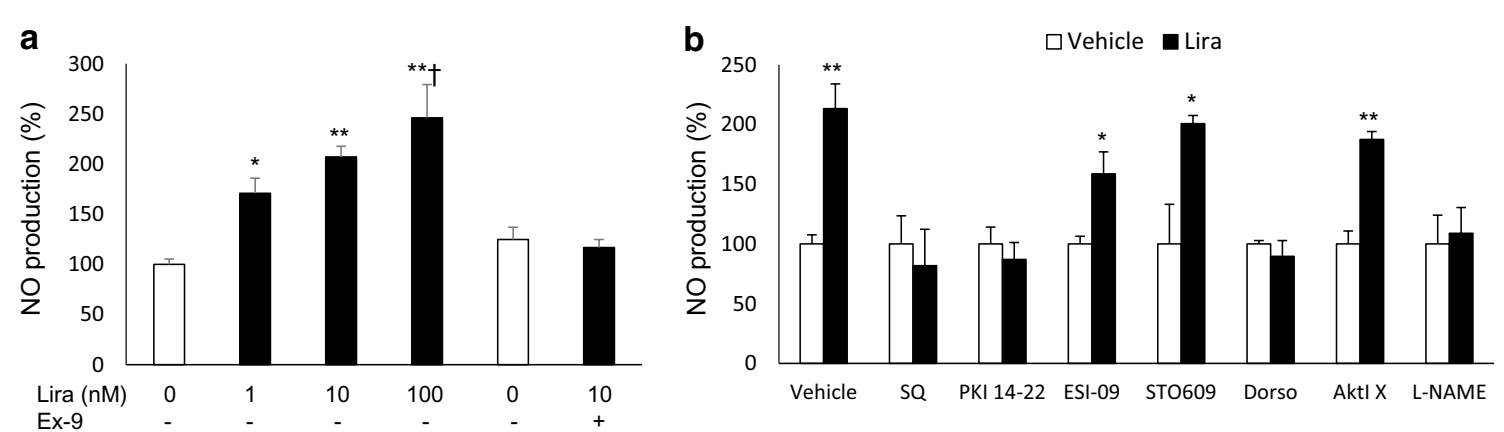

Fig. 5 Liraglutide stimulated NO production via the CAMP/PKA/AMPK/eNOS pathway in HUVECs. NO production by HUVECS was determined by measuring levels of the stable metabolites of $\mathrm{NO}\left(\mathrm{NO}_{2}\right.$ and $\left.\mathrm{NO}_{3}\right)$ in the culture medium. HUVECs were stimulated with the indicated concentrations of agents (saline or liraglutide $0.1-100 \mathrm{nmol} / \mathrm{L}$ ) for $2 \mathrm{~h}$, following serum starvation in M199, 0.3\% FBS, for $1 \mathrm{~h}$. Inhibitors were added 30 min prior to stimulation at the following concentrations: GLP-1R antagonist exendin-(9-39) (Ex-9), $100 \mathrm{nmol} / \mathrm{L}$; CAMP inhibitor SQ22536 (SQ), 100 Mmol/L; CAMPdependent protein kinase (PKA) inhibitor fragment 14-22 myristoylated trifluoroacetate salt (PKI[14-22]), 1 umol/L; exchange factor directly acti-

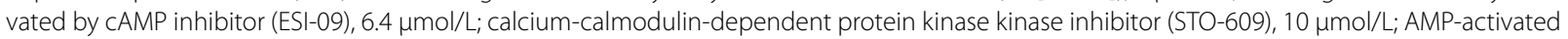
protein kinase (AMPK) inhibitor (dorsomorphine), $10 \mu \mathrm{mol} / \mathrm{L}$; Akt inhibitor 10-(4'-[[N-diethylamino]]butyl)-2-chlorophenoxazine (Aktl X), $5 \mu \mathrm{mol} / \mathrm{L}$; NOS inhibitor (L-NAME), $1 \mathrm{mmol} / \mathrm{L} ; \mathbf{a}$ effects of liraglutide and the Ex-9 GLP-1R antagonist on endothelial NO production, $2 \mathrm{~h}$ after stimulation; $\mathbf{b}$ effects of inhibitors of downstream molecules of GLP-1R on liraglutide-stimulated NO production; $n=4-6 ;{ }^{*} p<0.05$, ${ }^{* *}<0.01$ vs. vehicle; ${ }^{\dagger} p<0.05$ vs. liraglutide $1 \mathrm{nmol} / \mathrm{L}$

the effectiveness of the anti-restenotic and atherogenic outcomes of liraglutide treatment may be limited to the early phase of restenosis and atherosclerosis. Moreover, the findings indicate that liraglutide treatment should be initiated as early as possible to obtain maximal vasoprotective effect.

Our findings also provide insights into the source of endothelial NO responsible for the anti-restenotic effects of liraglutide. Injured arteries were completely denuded of endothelial cells as a result of wire injury in our model [21]. Although the denuded lumen is gradually covered by regenerating endothelial cells, this regeneration process was not completed during the early, short treatment. Thus, it is reasonable to assume that the endothelial NO is derived from intact endothelial cells from uninjured arteries.

It has been argued whether VECs express functional GLP-1Rs. Several studies support the direct action of GLP-1RAs on endothelial cells. GLP-1RAs have been shown to increase the endothelium-dependent vasodilation ex vivo, and endothelial $\mathrm{NO}$ production in vivo [27-30]. Although the GLP-1R/cAMP/PKA/AMPK/ eNOS pathway has been proposed to underlie these effects, the molecule that links PKA and AMPK has not been identified. A previous study has demonstrated the PKA-dependent phosphorylation of LKB1 by GLP1RA in VECs [30]; however, it remains unclear whether this effect is associated with the activation of AMPK. To address this, we first confirmed the previous findings: the liraglutide-stimulated endothelial NO production was blocked by inhibiting GLP-1R, cAMP, PKA,
AMPK, and eNOS in HUVECs. Next, we demonstrated that LKB-1 knockdown inhibited liraglutide-stimulated NO production and AMPK phosphorylation. Conversely, liraglutide-stimulated NO production was not affected by the inhibition of CaMKK- $\beta$, another molecule located upstream of AMPK [38]. Our findings indicate that LKB1 is essential for the enhancement of NO production by liraglutide, and acts upstream of AMPK.

Another aim of the present study was to determine whether the anti-restenotic effects of liraglutide were preserved under chronic severe hyperglycemia using $\mathrm{db} /$ $\mathrm{db}$ mice, a model of obesity-induced diabetes. It has been reported that chronic hyperglycemia leads to impaired GLP-1 activity in pancreatic $\beta$ cells $[31,45]$; however, evidence regarding the vascular role of GLP-1 under these conditions is limited, except for several studies in mice with mild hyperglycemia $[15,46]$. Unique to this study, and to minimize the influence of systemic effects, liraglutide was administered to $\mathrm{db} / \mathrm{db}$ mice at a dose that did not induce weight loss. Although the vascular expression of GLP-1R decreased in severely hyperglycemic $\mathrm{db} / \mathrm{db}$ mice, liraglutide suppressed neointimal hyperplasia, similar to its effect in normoglycemic wild-type mice. Interestingly, the effects of liraglutide on vascular cell proliferation and density after arterial injury differed between normoglycemic and hyperglycemic mice: in hyperglycemic mice, the suppression of vascular cell proliferation following liraglutide treatment was weaker than that in normoglycemic mice (60\% vs. $80 \%$ ); however, liraglutide treatment reduced vascular cell density in hyperglycemic, but not in normoglycemic mice $(60 \%$ 


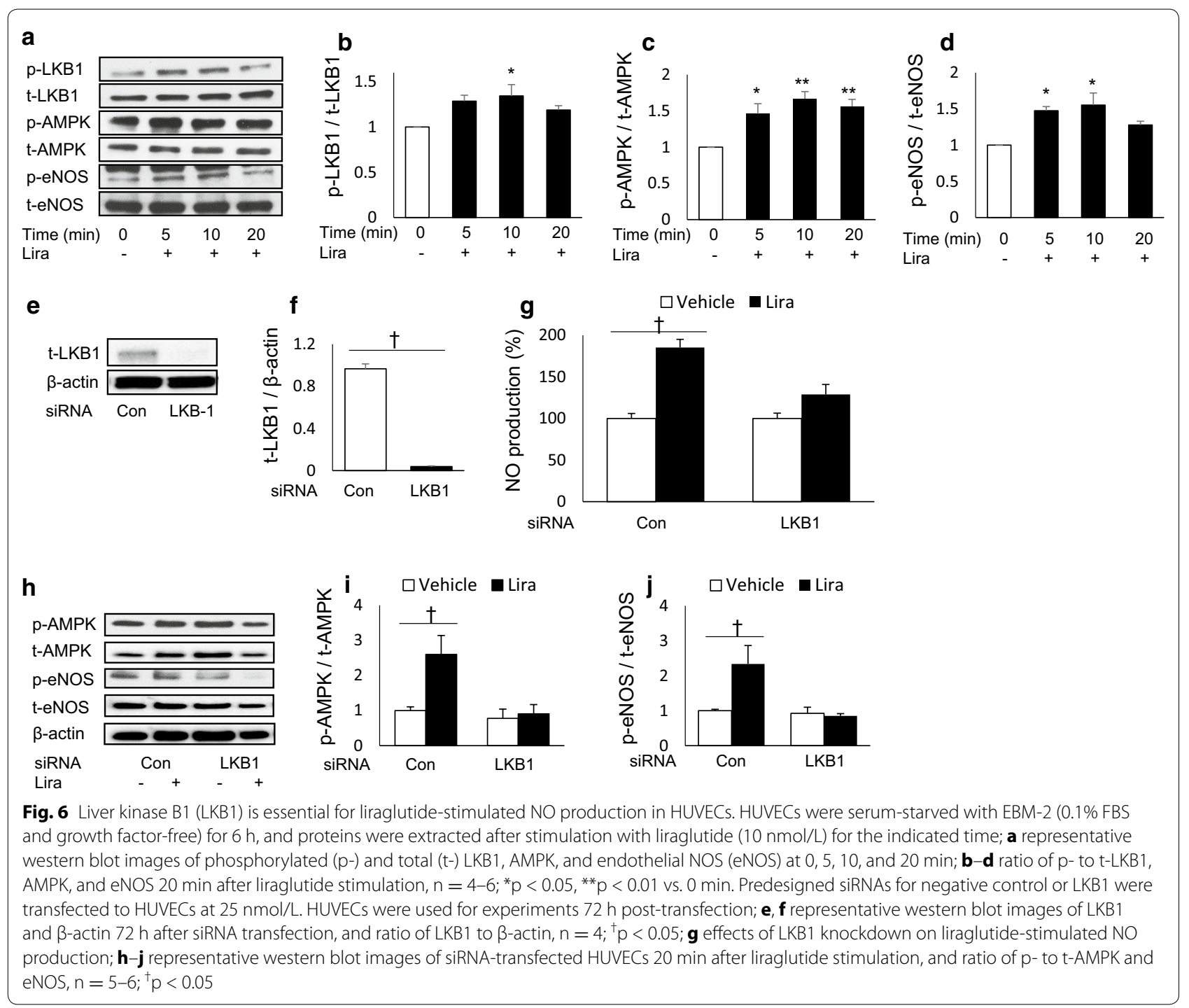

reduction). Cell density is associated with the deposition of the extracellular matrix (ECM), which contributes to the progression of neointimal hyperplasia. Liraglutide treatment also attenuated the injury-induced vascular expression of proinflammatory cytokines involved in vascular remodeling in hyperglycemic mice [47]. In addition, liraglutide treatment reduced the hyperglycemiaenhanced expression of $T g f-\beta$, which is associated with vascular complications in patients with diabetes [48, 49]; this change is consistent with the reduction in cell density. This suppression of inflammation and vascular ECM deposition may have contributed to the anti-restenotic effects of liraglutide in hyperglycemia.

Liraglutide treatment has been shown to reduce body weight gain in animals and humans. In the present study, liraglutide treatment at the high dose $(107 \mathrm{nmol} /$ $\mathrm{kg} /$ day), but not the low dose (17 nmol/ $\mathrm{kg} /$ day), significantly reduced body weight gain in $\mathrm{db} / \mathrm{db}$ mice; however, this effect of liraglutide was not observed in wild-type C57BL6 mice. It is possible that surgical stress from osmotic pump implantation and femoral artery wire injury could have masked this effect of liraglutide. C57BL6 mice that received no surgical stress showed body weight gains of approximately $2-4 \mathrm{~g} /$ month. Meanwhile, the mice that received osmotic pump implantation and femoral artery wire injury showed body weight gains of only approximately $0.5-1.5 \mathrm{~g} /$ month. Thus, liraglutide treatment did not induce further body weight reduction under conditions of surgical stress.

One of the limitations of the present study was the use of L-NAME to inhibit endothelial NO production in vivo. As L-NAME is a non-specific NOS inhibitor, it may have 


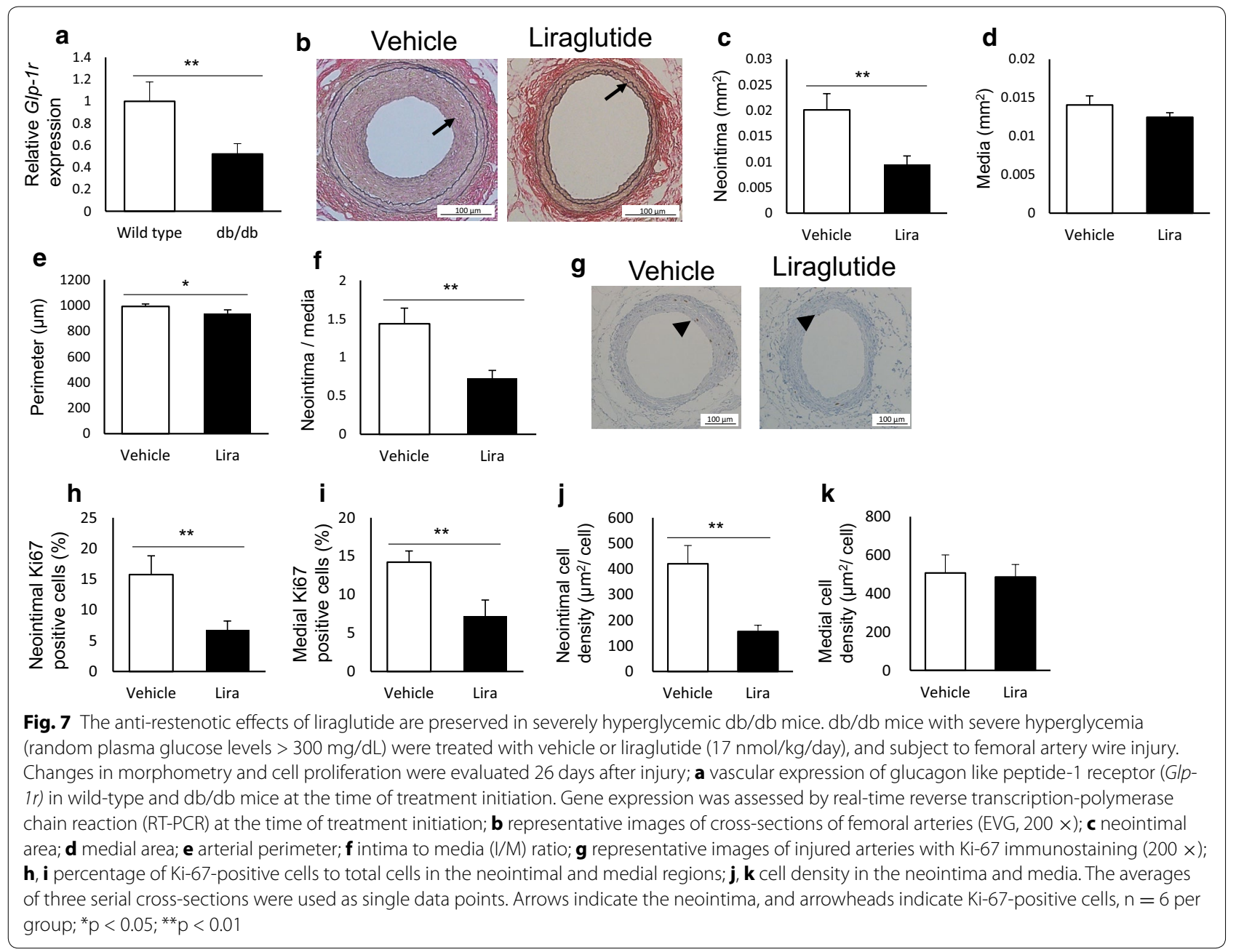

Table 5 Physiological and biochemical parameters of diabetic $\mathrm{db} / \mathrm{db}$ mice treated with vehicle or liraglutide

\begin{tabular}{lll}
\hline & Vehicle & Liraglutide (17 $\mathbf{~ m o l} / \mathbf{k g} /$ day $)$ \\
\hline Number & 6 & 6 \\
Food intake (g/day) & $7.6 \pm 0.2$ & $6.7 \pm 0.3$ \\
Water intake (g/dy) & $10.2 \pm 0.2$ & $9.6 \pm 0.2$ \\
Initial BW (g) & $40.6 \pm 0.4$ & $39.5 \pm 0.4$ \\
Final BW (g) & $45.5 \pm 0.9$ & $43.9 \pm 0.7$ \\
BW change (g) & $4.9 \pm 0.7$ & $4.4 \pm 0.7$ \\
Heart rate (beats/min) & $584 \pm 7$ & $624 \pm 7^{*}$ \\
SBP (mmHg) & $135 \pm 8$ & $141 \pm 3$ \\
DBP (mmHg) & $76 \pm 7$ & $69 \pm 6$ \\
HbA1c (\%) & $9.5 \pm 0.3$ & $9.1 \pm 0.8$ \\
FPG (mg/dL) & $504 \pm 41$ & $390 \pm 69$ \\
TC (mg/dL) & $121 \pm 7$ & $126 \pm 3$ \\
TG (mg/dL) & $117 \pm 12$ & $105 \pm 6$ \\
Active GLP-1 (pmol/L) & $4.2 \pm 1.0$ & $6.8 \pm 0.5^{*}$
\end{tabular}

Food and water intake were measured throughout the experimental period. The other parameters were evaluated at the end of the experiment, except for initial BW ${ }^{*} p<0.05$ vs. vehicle
Table 6 Correlations between neointimal and medial areas with proliferating and total cell counts in $\mathrm{db} / \mathrm{db}$ mice

\begin{tabular}{lccccc}
\hline Neointimal area & $\mathbf{r}$ & $\mathbf{p}$ & Medial area & $\mathbf{r}$ & $\mathbf{p}$ \\
\hline $\begin{array}{l}\text { Combined } \\
\text { Intima }\end{array}$ & \multicolumn{5}{c}{$\begin{array}{c}\text { Combined } \\
\text { Intima }\end{array}$} \\
$\quad$ Ki67+ cells & 0.80 & $<0.0001$ & Ki67+ cells & 0.20 & 0.32 \\
$\quad$ Total cells & 0.83 & $<0.0001$ & Total cells & 0.37 & 0.05 \\
Media & & \multicolumn{5}{c}{ Media } \\
$\quad$ Ki67+ cells & 0.27 & 0.16 & Ki67+ cells & 0.38 & 0.05 \\
Total cells & 0.00 & 0.99 & Total cells & 0.45 & 0.01 \\
\hline
\end{tabular}

$r$ indicates Pearson's correlation coefficient. Twenty-eight sections, taken from 10 mice, were used for analysis

masked the potential effects of liraglutide on other NOS isoforms: the inducible and the neuronal NOS [50]. In addition, eNOS in VSMCs may be involved in the antirestenotic effects of liraglutide. eNOS is expressed exclusively in ECs. However, recent studies have demonstrated that VSMCs express eNOS under hypoxic conditions 

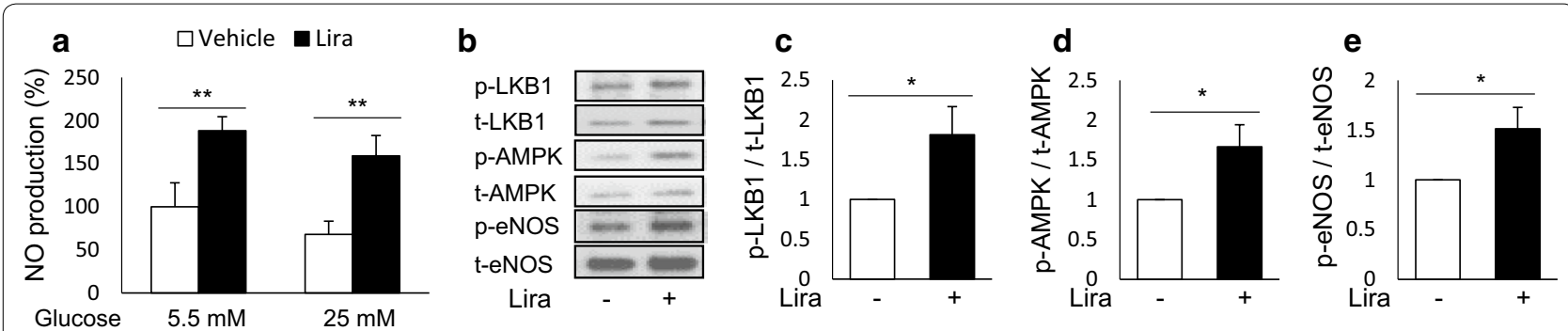

Fig. 8 Effects of liraglutide on NO production under hyperglycemic conditions. HUVECs were cultured in normal (5.5 mmol/L) or high-glucose $(25 \mathrm{mmol} / \mathrm{L})$ medium $48 \mathrm{~h}$ prior to the experiments; a NO production $2 \mathrm{~h}$ after vehicle or liraglutide $(10 \mathrm{nmol} / \mathrm{L})$ stimulation under normal or high glucose conditions, $n=4-6$; $\mathbf{b}$ representative western blot images of HUVECs cultured in high-glucose, stimulated with vehicle or liraglutide $(10 \mathrm{nmol} / \mathrm{L})$ for $20 \mathrm{~min}$, and the ratio of $\mathrm{p}$ - to t-LKB1 (c), AMPK (d), and eNOS $(\mathbf{e}), \mathrm{n}=6-8 ;{ }^{*} \mathrm{p}<0.05 ;{ }^{* *} \mathrm{p}<0.01$

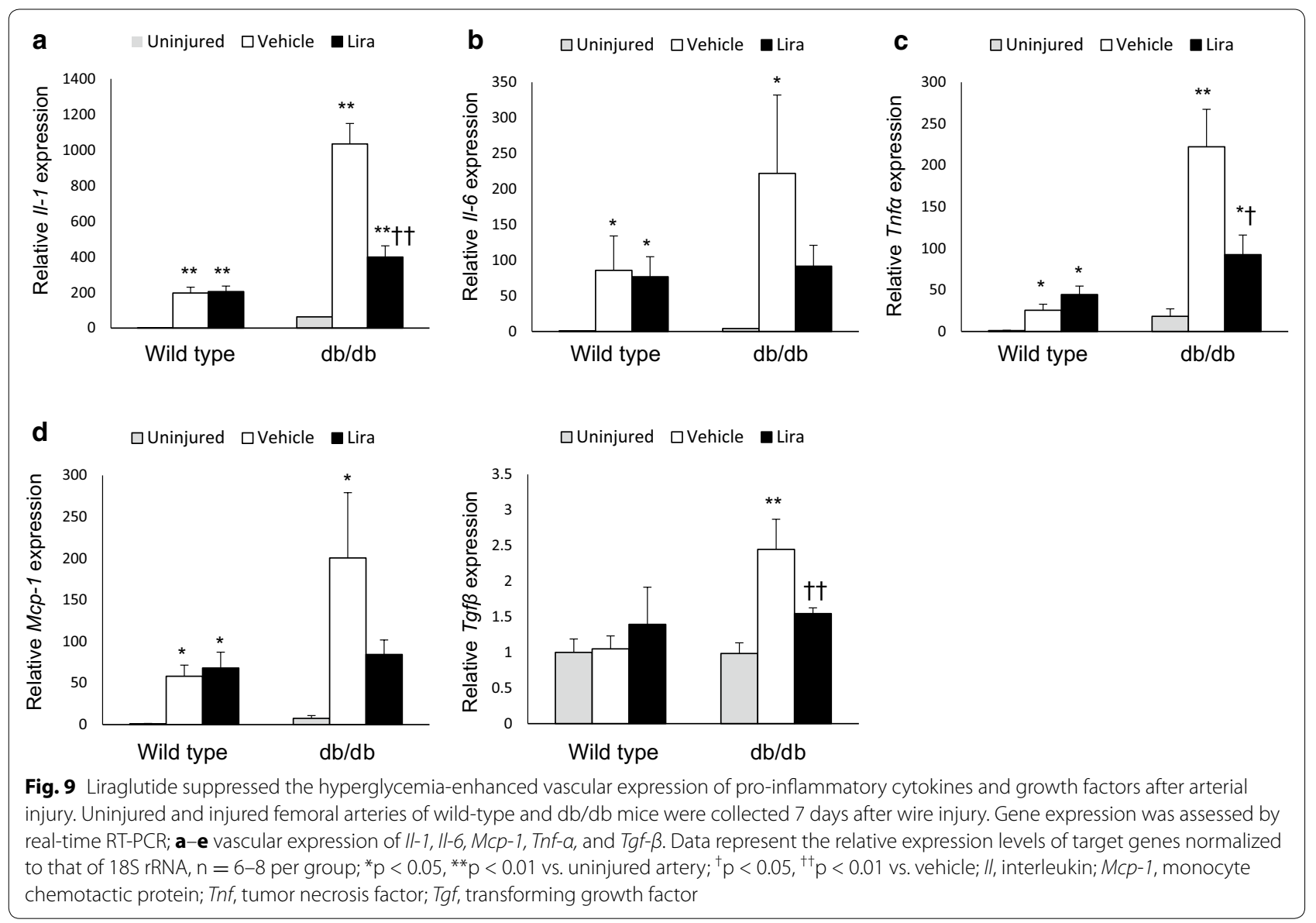

via promoter demethylation [51], and that liraglutide increases eNOS expression in cultured rat pulmonary artery smooth muscle cells [52]. For a better understanding of the role of eNOS at the molecular level, a study employing cell-specific gene deletion, including an inducible Cre-loxP or tetracycline-controlled transcriptional regulation system, is required [53, 54]. Moreover, it remains unclear whether liraglutide exerts additive anti-restenotic effects in DES. Our findings justify further studies employing larger animals, such as rabbits and pigs, which would provide better clinical models. Another concern is potential adverse effects of high-dose liraglutide on the cardiovascular system. It is reported that treatment with GLP-1RAs including liraglutide increases heart rate in animal and humans [10, 11, 5557]. In addition, liraglutide treatment has been shown 
not to improve the systolic function of the left ventricle in patients with type 2 diabetes and stable coronary artery disease, indicating that liraglutide treatment exerts positive chronotropic, but not inotropic effects on the heart [58]. Thus, exceedingly high levels of liraglutide could result in adverse effects on the cardiovascular system by positive chronotropic effects in acute settings. Our findings indicate that a higher dose of liraglutide is more effective at suppressing restenosis; however, an optimum dose of liraglutide balancing anti-restenotic and positive chronotropic effects needs to be determined.

\section{Conclusions}

In conclusion, we demonstrate that endothelial cells are the target of liraglutide, which suppresses restenosis via endothelial NO. This anti-restenotic effect is retained under severe hyperglycemia, and earlier initiation of GLP-1RA treatment may lead to a better vascular outcome. To our knowledge, the present study is the first to report that the anti-restenotic effects of liraglutide are abolished by the L-NAME NOS inhibitor in vivo, and that LKB1 is essential for liraglutide-stimulated endothelial NO production in vitro. Our findings provide an evidence base for a future clinical trial to determine whether treatment with GLP-1RAs represents potentially effective pharmacological therapy, following PTA with DES in patients with diabetes.

\section{Additional file}

Additional file 1. Additional figures (Figs. S1-S4).

\section{Acknowledgements}

We greatly appreciate Hiroko Takeuchi and Tomomi Saito, Division of Diabetes, Metabolism, and Endocrinology at the Showa University School of Medicine, for their excellent technical support. We also thank Noriko Sato, Yuki Tanabe, Hiroto Sasamori, and Satoshi Yamamura of the Division of Diabetes, Metabolism, and Endocrinology at the Showa University School of Medicine for their kind support.

\section{Competing interests}

TH received lecture fees from MSD KK, Novartis Pharma KK, Novo Nordisk Pharma Ltd., Sanwa Kagaku Kenkyusho Co., LTD., Kowa Co., LTD., Eli Lilly Japan KK, Mitsubishi Tanabe Pharma Co., and Ono Pharmaceutical Co., Ltd. All other authors declare that they have no competing interests.

\section{Availability of data and materials}

The datasets used and/or analysed during the current study are available from the corresponding author on reasonable request.

\section{Consent for publication}

All authors and HT, TS, NS, YT, HS, and SY in Acknowledgement consent to the publication of this article.

\section{Ethics approval and consent to participate}

The study design was approved by the animal care committee of Showa University School of Medicine (\#04142). Animal experiments were performed in strict adherence to the Guide for the Care and Use of Laboratory Animals (8th edition, 2011; Office of laboratory animal welfare, National Institutes of Health, MD, USA). The consent to participate is not applicable to this study.

\section{Funding}

This study was financially supported in part by unlimited grants from MSD KK, Novartis Pharma KK, Novo Nordisk Pharma Ltd., Sanwa Kagaku Kenkyusho Co., LTD., Kowa Co., LTD., Eli Lilly Japan KK, and Mitsubishi Tanabe Pharma Co. However, they played no role in the design of the study; collection, analysis, and interpretation of data; or in writing the manuscript, and did not have access to data stemming from this study.

\section{Publisher's Note}

Springer Nature remains neutral with regard to jurisdictional claims in published maps and institutional affiliations.

Received: 20 July 2017 Accepted: 21 September 2017

Published online: 02 October 2017

\section{References}

1. Htike ZZ, Zaccardi F, Papamargaritis D, Webb DR, Khunti K, Davies MJ. Efficacy and safety of glucagon-like peptide-1 receptor agonists in type 2 diabetes: a systematic review and mixed-treatment comparison analysis. Diabetes Obes Metab. 2017;19:524-36.

2. Drucker DJ. Incretin action in the pancreas: potential promise, possible perils, and pathological pitfalls. Diabetes. 2013;62:3316-23.

3. Tashiro Y, Sato K, Watanabe T, Nohtomi K, Terasaki M, Nagashima M, et al. A glucagon-like peptide-1 analog liraglutide suppresses macrophage foam cell formation and atherosclerosis. Peptides. 2014;54:19-26.

4. Nagashima M, Watanabe T, Terasaki M, Tomoyasu M, Nohtomi K, Kim-Kaneyama J, et al. Native incretins prevent the development of atherosclerotic lesions in apolipoprotein E knockout mice. Diabetologia. 2011;54:2649-59.

5. Bisgaard LS, Bosteen MH, Fink LN, Sørensen CM, Rosendahl A, Mogensen CK, et al. Liraglutide reduces both atherosclerosis and kidney inflammation in moderately uremic LDLr-/- mice. PLOS ONE. 2016. doi:10.1371/ journal.pone.0168396.

6. Arakawa M, Mita T, Azuma K, Ebato C, Goto H, Nomiyama T, et al. Inhibition of monocyte adhesion to endothelial cells and attenuation of atherosclerotic lesion by a glucagon-like peptide-1 receptor agonist, exendin-4. Diabetes. 2010;59:1030-107. 
7. Jojima T, Uchida K, Akimoto K, Tomotsune T, Yanagi K, lijima T, et al. Liraglutide, a GLP-1 receptor agonist, inhibits vascular smooth muscle cell proliferation by enhancing AMP-activated protein kinase and cell cycle regulation, and delays atherosclerosis in ApoE deficient mice. Atherosclerosis. 2017;261:44-51.

8. Gaspari T, Welungoda I, Widdop RE, Simpson RW, Dear AE. The GLP-1 receptor agonist liraglutide inhibits progression of vascular disease via effects on atherogenesis, plaque stability and endothelial function in an ApoE(-/-) mouse model. Diab Vasc Dis Res. 2013;10:353-60.

9. Wang Y, Parlevliet ET, Geerling JJ, van der Tuin SJ, Zhang H, Bieghs V, et al. Exendin-4 decreases liver inflammation and atherosclerosis development simultaneously by reducing macrophage infiltration. Br J Pharmacol. 2014;171:723-34

10. Marso SP, Daniels GH, Brown-Frandsen K, Kristensen P, Mann JF, Nauck MA, et al. Liraglutide and cardiovascular outcomes in type 2 diabetes. $\mathrm{N}$ Engl J Med. 2016;375:311-22.

11. Marso SP, Bain SC, Consoli A, Eliaschewitz FG, Jódar E, Leiter LA, et al. Semaglutide and cardiovascular outcomes in patients with type 2 diabetes. N Engl J Med. 2016;375:1834-44

12. Goto H, Nomiyama T, Mita T, Yasunari E, Azuma K, Komiya K, et al. Exendin-4, a glucagon-like peptide-1 receptor agonist, reduces intimal thickening after vascular injury. Biochem Biophys Res Commun. 2011;405:79-84.

13. Hirata Y, Kurobe H, Nishio C, Tanaka K, Fukuda D, Uematsu E, et al. Exendin-4, a glucagon-like peptide-1 receptor agonist, attenuates neointimal hyperplasia after vascular injury. Eur J Pharmacol. 2013;699:106-11.

14. Eriksson L, Saxelin R, Röhl S, Roy J, Caidahl K, Nyström T, et al. Glucagonlike peptide-1 receptor activation does not affect re-endothelialization but reduces intimal hyperplasia via direct effects on smooth muscle cells in a nondiabetic model of arterial injury. J Vasc Res. 2015;52:41-52.

15. Lim S, Lee GY, Park HS, Lee DH, Tae Jung O, Kyoung Min K, et al. Attenuation of carotid neointimal formation after direct delivery of a recombinant adenovirus expressing glucagon-like peptide-1 in diabetic rats. Cardiovasc Res. 2017;113:183-94.

16. Korshunov VA, Schwartz SM, Berk BC. Vascular remodeling: hemodynamic and biochemical mechanisms underlying Glagov's phenomenon. Arterioscler Thromb Vasc Biol. 2007;27:1722-8.

17. Kokkinidis DG, Waldo SW, Armstrong EJ. Treatment of coronary artery in-stent restenosis. Expert Rev Cardiovasc Ther. 2017;15:191-202.

18. Kang SH, Park KW, Kang DY, Lim WH, Park KT, Han JK, et al. Biodegradablepolymer, drug-eluting stents vs. bare metal stents vs. durable-polymer drug-eluting stents: a systematic review and Bayesian approach network meta-analysis. Eur Heart J. 2014;35:1147-58.

19. Aronson D, Edelman ER. Revascularization for coronary artery disease in diabetes mellitus: angioplasty, stents and coronary artery bypass grafting. Rev Endocr Metab Disord. 2010;11:75-86.

20. Stettler C, Allemann S, Wandel S, Kastrati A, Morice MC, Schomig A, et al. Drug eluting and bare metal stents in people with and without diabetes: collaborative network meta-analysis. BMJ. 2008;337:a1331-4.

21. Sata M, Maejima Y, Adachi F, Fukino K, Saiura A, Sugiura S, et al. A mouse model of vascular injury that induces rapid onset of medial cell apoptosis followed by reproducible neointimal hyperplasia. J Mol Cell Cardiol. 2000:32:2097-104.

22. Shi L, Ji Y, Jiang $X$, Zhou L, Xu Y, Li Y, et al. Liraglutide attenuates high glucose-induced abnormal cell migration, proliferation, and apoptosis of vascular smooth muscle cells by activating the GLP-1 receptor, and inhibiting ERK1/2 and PI3 K/Akt signaling pathways. Cardiovasc Diabetol. 2015;14:18.

23. Nagayama K, Kyotani Y, Zhao J, Ito S, Ozawa K, Bolstad FA, et al. Exendin-4 prevents vascular smooth muscle cell proliferation and migration by angiotensin II via the inhibition of ERK1/2 and JNK signaling pathways. PLoS ONE. 2015. doi:10.1371/journal.pone.0137960.

24. Otsuka F, Finn AV, Yazdani SK, Nakano M, Kolodgie FD, Virmani R. The importance of the endothelium in atherothrombosis and coronary stenting. Nat Rev Cardiol. 2012;9:439-53.

25. Farooq V, Gogas BD, Serruys PW. Restenosis: delineating the numerous causes of drug-eluting stent restenosis. Circ Cardiovasc Interv. 2011:4:195-205.

26. Kauser K, da Cunha V, Fitch R, Mallari C, Rubanyi GM. Role of endogenous nitric oxide in progression of atherosclerosis in apolipoprotein E-deficient mice. Am J Physiol Heart Circ Physiol. 2000;278:H1679-85.
27. Ke J, Liu Y, Yang J, Lu R, Tian Q, Hou W, et al. Synergistic effects of metformin with liraglutide against endothelial dysfunction through GLP-1 receptor and PKA signalling pathway. Sci Rep. 2017. doi:10.1038/srep41085.

28. Ding L, Zhang J. Glucagon-like peptide-1 activates endothelial nitric oxide synthase in human umbilical vein endothelial cells. Acta Pharmacol Sin. 2012;33:75-81.

29. Koska J, Sands M, Burciu C, D'Souza KM, Raravikar K, Liu J, et al. Exenatide protects against glucose- and lipid-induced endothelial dysfunction: evidence for direct vasodilation effect of GLP-1 receptor agonists in humans. Diabetes. 2015;64:2624-35.

30. Liu L, Liu J, Wong WT, Tian XY, Lau CW, Wang YX, et al. Dipeptidyl peptidase 4 inhibitor sitagliptin protects endothelial function in hypertension through a glucagon-like peptide 1-dependent mechanism. Hypertension. 2012;60:833-41.

31. Kjems LL, Holst JJ, Vølund A, Madsbad S. The influence of GLP-1 on glucose-stimulated insulin secretion: effects on beta-cell sensitivity in type 2 and nondiabetic subjects. Diabetes. 2003;52:380-6.

32. Kohashi K, Hiromura M, Mori Y, Terasaki M, Watanabe T, Kushima H, et al. A dipeptidyl peptidase-4 inhibitor but not incretins suppresses abdominal aortic aneurysms in angiotensin Il-infused apolipoprotein E-null mice. J Atheroscler Thromb. 2016;23:441-54.

33. Igawa S, Hayashi I, Tanaka N, Hiruma H, Majima M, Kawakami T, et al. Nitric oxide generated by iNOS reduces deformability of lewis lung carcinoma cells. Cancer Sci. 2004;95:342-7.

34. Yu X, Li F, Klussmann E, Stallone JN, Han G. G protein-coupled estrogen receptor 1 mediates relaxation of coronary arteries via CAMP/ PKA-dependent activation of MLCP. Am J Physiol Endocrinol Metab. 2014;15(307):E398-407

35. Spirli C, Okolicsanyi S, Fiorotto R, Fabris L, Cadamuro M, Lecchi S, et al. ERK1/2-dependent vascular endothelial growth factor signaling sustains cyst growth in polycystin-2 defective mice. Gastroenterology. 2010;138:360-71

36. Almahariq M, Tsalkova T, Mei FC, Chen H, Zhou J, Sastry SK, et al. A novel EPAC-specific inhibitor suppresses pancreatic cancer cell migration and invasion. Mol Pharmacol. 2013;83:122-8.

37. Calay D, Vind-Kezunovic D, Frankart A, Lambert S, Poumay Y, Gniadecki R. Inhibition of Akt signaling by exclusion from lipid rafts in normal and transformed epidermal keratinocytes. J Invest Dermatol. 2010;130:1136-45.

38. Wang W, Diamond SL. Does elevated nitric oxide production enhance the release of prostacyclin from shear stressed aortic endothelial cells? Biochem Biophys Res Commun. 1997;233:748-51.

39. Hawley SA, Pan DA, Mustard KJ, Ross L, Bain J, Edelman AM, et al. Calmodulin-dependent protein kinase kinase-beta is an alternative upstream kinase for AMP-activated protein kinase. Cell Metab. 2005;2:9-19.

40. Pereira S, Park E, Mori Y, Haber CA, Han P, Uchida T, et al. FFA-induced hepatic insulin resistance in vivo is mediated by PKC $\delta$, NADPH oxidase, and oxidative stress. Am J Physiol Endocrinol Metab. 2014;307:E34-46.

41. Peotta VA, Vasquez EC, Meyrelles SS. Cardiovascular neural reflexes in L-NAME-induced hypertension in mice. Hypertension. 2001;38:555-9.

42. Guo J, Breen DM, Pereira TJ, Dalvi PS, Zhang H, Mori Y, et al. The effect of insulin to decrease neointimal growth after arterial injury is endothelial nitric oxide synthase-dependent. Atherosclerosis. 2015;241:111-20.

43. Pearce CG, Najjar SF, Kapadia MR, Murar J, Eng J, Lyle B, et al. Beneficial effect of a short-acting $\mathrm{NO}$ donor for the prevention of neointimal hyperplasia. Free Radic Biol Med. 2008;44:73-81.

44. Chen L, Daum G, Forough R, Clowes M, Walter U, Clowes AW. Overexpression of human endothelial nitric oxide synthase in rat vascular smooth muscle cells and in balloon-injured carotid artery. Circ Res. 1998:82:862-70.

45. Xu G, Kaneto H, Laybutt DR, Duvivier-Kali VF, Trivedi N, Suzuma K, et al. Downregulation of GLP-1 and GIP receptor expression by hyperglycemia: possible contribution to impaired incretin effects in diabetes. Diabetes. 2007:56:1551-8.

46. Panjwani N, Mulvihill EE, Longuet C, Yusta B, Campbell JE, Brown TJ, et al. GLP-1 receptor activation indirectly reduces hepatic lipid accumulation but does not attenuate development of atherosclerosis in diabetic male ApoE(-/-) mice. Endocrinology. 2013;154:127-39.

47. Libby P, Schwartz D, Brogi E, Tanaka H, Clinton SK. A cascade model for restenosis. A special case of atherosclerosis progression. Circulation. 1992;86:I||47-52. 
48. Khan R, Agrotis A, Bobik A. Understanding the role of transforming growth factor-beta1 in intimal thickening after vascular injury. Cardiovasc Res. 2007;74:223-34.

49. Gleissner CA, Galkina E, Nadler JL, Ley K. Mechanisms by which diabetes increases cardiovascular disease. Drug Discov Today Dis Mech. 2007:4:131-40.

50. Förstermann U, Sessa WC. Nitric oxide synthases: regulation and function. Eur Heart J. 2012;33:829-37.

51. Tan $X$, Feng L, Huang $X$, Yang $Y$, Yang C, Gao Y. Histone deacetylase inhibitors promote eNOS expression in vascular smooth muscle cells and suppress hypoxia-induced cell growth. J Cell Mol Med. 2017. doi:10.1111/ jcmm.13122.

52. Lee Mei-Yueh, Tsai Kun-Bow, Hsu Jong-Hau, Shin Shyi-Jang, Jiunn-Ren Wu, Yeh Jwu-Lai. Liraglutide prevents and reverses monocrotaline-induced pulmonary arterial hypertension by suppressing ET-1 and enhancing eNOS/sGC/PKG pathways. Sci Rep. 2016;6:31788

53. Feil R, Wagner J, Metzger D, Chambon P. Regulation of Cre recombinase activity by mutated estrogen receptor ligand-binding domains. Biochem Biophys Res Commun. 1997;237:752-7.
54. Gossen M, Bujard H. Tight control of gene expression in mammalian cells by tetracycline-responsive promoters. Proc Natl Acad Sci USA. 1992:89:5547-51.

55. Zhou X, Huang CH, Lao J, Pocai A, Forrest G, Price O, et al. Acute hemodynamic and renal effects of glucagon-like peptide 1 analog and dipeptidyl peptidase-4 inhibitor in rats. Cardiovasc Diabetol. 2015;14:29.

56. Nielsen R, Jorsal A, Iversen P, Tolbod LP, Bouchelouche K, Sørensen J, et al. Effect of liraglutide on myocardial glucose uptake and blood flow in stable chronic heart failure patients: a double-blind, randomized, placebo-controlled LIVE sub-study. J Nucl Cardiol. 2017. doi:10.1007/ s12350-017-1000-2 (Epub ahead of print)

57. Pfeffer MA, Claggett B, Diaz R, Dickstein K, Gerstein HC, Køber LV, et al. Lixisenatide in patients with type 2 diabetes and acute coronary syndrome. N Engl J Med. 2015;373:2247-57.

58. Kumarathurai $P$, Anholm C, Nielsen OW, Kristiansen OP, Mølvig J, Madsbad $S$, et al. Effects of the glucagon-like peptide-1 receptor agonist liraglutide on systolic function in patients with coronary artery disease and type 2 diabetes: a randomized double-blind placebo-controlled crossover study. Cardiovasc Diabetol. 2016;15:105.

\section{Submit your next manuscript to BioMed Central and we will help you at every step:}

- We accept pre-submission inquiries

- Our selector tool helps you to find the most relevant journal

- We provide round the clock customer support

- Convenient online submission

- Thorough peer review

- Inclusion in PubMed and all major indexing services

- Maximum visibility for your research

Submit your manuscript at www.biomedcentral com/submit 